\title{
Opt-Out Consent at Different Levels of Attitude to Organ Donation: A Household Survey in Qatar
}

This article was published in the following Dove Press journal:

Journal of Multidisciplinary Healthcare

\author{
Rajvir Singh (D) \\ Betsy Varughese ${ }^{2}$ \\ Ayman El-Menyar (D) ${ }^{3}$ \\ Saad Shahbal' \\ Yousuf Al Maslamani ${ }^{4}$ \\ Amar M Salam (DD \\ Hassan Al Thani ${ }^{3}$ \\ 'Cardiology Research Center, Heart \\ Hospital, Hamad Medical Corporation \\ (HMC), Doha, Qatar; ${ }^{2}$ Gastroenterology \\ \& Hepatology, HMC, Doha, Qatar; \\ ${ }^{3}$ Trauma \& Vascular Surgery, HMC, Doha, \\ Qatar; ${ }^{4}$ Hamad General Hospital (HGH), \\ HMC, Doha, Qatar; ${ }^{5}$ Department of \\ Cardiology \& Cardiovascular Surgery \\ Hamad Medical Corporation, Doha, \\ Qatar
}

Purpose: Demand for an organ transplant is surpassing the number of organ donors and hence increasing waiting lists worldwide, compelling many countries to adopt an opt-out consent system for organ donation. Opt-out is used in several European countries and has increased organ registration rate. No study on this subject has been published from the gulf region to associate sociodemographic characteristics, knowledge, attitude, beliefs, and intention domains regarding an opt-out consent for organ donation.

Materials and Methods: A household survey was conducted between October and November 2016 using a validated questionnaire. Integer codes were assigned for qualitative data to interpret results at par with quantitative data for each domain to allow data for advanced statistical analysis.

Results: Of 1044 surveyed participants, 724 (69.34\%) those aged $37.7 \pm 10.4$ agreed to adopting an opt-out consent system of which 231 (29.4\%) were Qatari citizens and 353 $(48.8 \%)$ were males. Mean levels of indices such as attitude, behavioral beliefs, and intention domains to organ donation were found higher in opt out participants. After adjusting statistical significant variables, multivariate analysis showed that attitude index was associated to opt out system (OR: 16.7, 95\% C.I.:10.6-26.3, $\mathrm{p}=0.001)$ whereas; knowledge index (OR: $0.25,95 \%$ C.I.: $0.07-0.83, \mathrm{p}=0.03$ ), behavioral beliefs (OR: $0.55,95 \%$ C.I.: $0.35-0.86$, $\mathrm{p}=0.009$ ) and intention indices (OR: $0.42,95 \%$ C.I.: $0.20-0.87, \mathrm{p}=0.02$ ) were associated with opt-in system for organ donation in Qatar. Regression model was able to discriminate (AUC: $84 \%$, $95 \%$ C.I.: $81 \%$ to $87 \%$ ) for opt-out consent. Future probabilities for opt-out consent were $0.80,0.88,0.92,0.95,0.96,0.97,0.99$ and 0.993 for $0.20,0.30,0.40,0.50,0.60,0.70$, 0.80 and 0.90 attitude levels after using 200 re-samples to make traditional multivariate regression model to realistic model for the population.

Conclusion: The majority of the survey participants showed a good attitude but less knowledge, behavioral beliefs, and intention towards adopting an opt-out system for organ donation in Qatar.

Keywords: opt-in \& opt-out consent system, organ donation, organ transplant, knowledge, attitude, beliefs, intention domains

\section{Introduction}

Global ongoing efforts are being made to increase the availability for transplantation of living or deceased donor organs to meet the high demand of patients on the waiting lists. ${ }^{1-3}$ A gap between supply and demand for donated organs remains as a low consent rate has been identified as a major limiting factor. ${ }^{4}$ Many countries have adopted an optout consent system for organ donation where anyone is considered as an organ donor unless they have expressed their wish not to be a donor which is different from the optin consent system where only people who have given explicit consent are considered as
Correspondence: Rajvir Singh

Cardiology Research Center, Heart

Hospital, Hamad Medical Corporation

(HMC), Doha, Qatar

Tel +974-44390442

Email rajvir.aiims@gmail.com
Journal of Multidisciplinary Healthcare 202I:14 40I-4I0

401

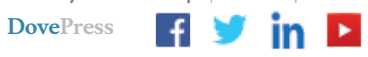

(c) (i) (5) 2021 singh et al. This work is published and licensed by Dove Medical Press Limited. The full terms of this license are available at https://www.dovepress.com/terms.php C. you hereby accept the Terms. Non-commercial uses of the work are permitted without any further permission from Dove Medical Press Limited, provided the work is properly attributed. For permission for commercial use of this work, please see paragraphs 4.2 and 5 of our Terms (https://www.dovepress.com/terms.php). 
donors. ${ }^{5}$ There is also a debate on who has the ultimate power to donate or withhold tissues or organs in situations where individuals and families disagree with each other. ${ }^{6}$ Individuals may have negative rights to withhold organ donation, but no positive right to donate organs without their family's consent. ${ }^{6}$ Similarly, the family may have a negative right to withhold organ donation, but no positive right to donate organs without the individual's permission. ${ }^{6}$ Even surgeons are not permitted to remove organs or tissues from the deceased body without consent.

It is anticipated that presumed consent legislation will increase the number of donors possibly due to its default effect $^{7}$ making it easier for the family to take decisions in traumatic circumstances. ${ }^{8}$ For example, Germany, which has an opt-in program, has deceased organ donation rate of 10.4 per million population. In contrast, neighboring Austria, which has a society and economic development like that of Germany, follows an opt-out system has a higher rate of deceased organ donation rate of 24.8 per million population., ${ }^{9,10}$ A recent study on organ donation in Qatar's household population showed that very few people are only registered for organ donation. ${ }^{11}$ At the same time, many people had expressed their faith in the health care facility and were ready to take transplantation treatment in Qatar, if needed, instead of going abroad. ${ }^{11}$ Hence, we sought the public opinion of the household population about organ donation registration in Qatar.

\section{Materials and Methods}

This is secondary data analyzed from a prospective cross-sectional survey on organ donation conducted on 1044 household respondents in all the eight Qatar municipalities between October and November 2016. ${ }^{11}$ All municipalities were divided into small geographical areas called Primary Sampling Units (PSUs) having 75 Households Qatari and 100 Households non-Qatari per PSU. A two-stage systematic random sampling design was used, selecting Primary Sampling Units (PSUs) at the first stage and a sample of households within each selected PSU at the second stage. Fourteen Qatari and 38 non-Qatari PSUs were selected proportional to population from the sampling frame. The survey was conducted among the household population by face-to-face interviews using a validated questionnaire based on Theory of Planned Behavior (TPB). ${ }^{12-14}$ A team consisting of 29 bilingual female interviewers/research assistants and supervisors fluent in the relevant language and with experience socializing in the community and translating conducted the interviews. Quality control measures such as extensive training for the interviewers on the recruitment process, explaining the questionnaire items, and data collection were applied to ensure consistency of the collected data. Face to face interview was conducted after the verbal consent of the participant to minimize the interference during the interview. The detailed description of data collection, calculation of domain indices, and coding of the domain items are described. ${ }^{11}$

\section{Verbal Informed Consent}

Verbal informed consent was obtained from study participants before the interview and was made available in relevant languages. The consent was approved by the Institutional Review Board (IRB), HMC. The document was included a description of the research and its objectives, a statement clarifying the implications of the research subject's confidentiality, information about how the subject can obtain answers to pertinent research questions, and a statement about the voluntary nature of study participation. The interviewer answered participants' all questions regarding the study before enrolling in the survey. Each interview had taken 30-45 minutes approximately. Declaration of Helsinki guidelines to conduct the prospective survey were followed. Ethical approval of the study was taken from the IRB (Ref. No. 14,227/14), Medical Research Center, HMC, Doha, Qatar. ${ }^{11}$

\section{Sample Size}

We assumed 50\% (as no figure is available in Qatar about the general population for organ donation knowledge) of the population will know about the organ donation or will willing to donate with 5\% absolute error keeping 95\% C. I. and design effect 2 to avoid biases of clustering, sample size $768 \approx 800$ households would have been enough to enroll in the study. Sample size (n) was calculated using the formula, $\mathrm{n}=\left\{\right.$ Design effect $* \mathrm{~N}(\mathrm{p}(1-\mathrm{p})\} /\left\{\mathrm{d}^{2} / \mathrm{Z}^{2}{ }_{1-\alpha / 2} *(\mathrm{~N}\right.$ $\left.-1)+p^{*}(1-p)\right\}$, where $N$ is Qatar general population eligible for organ donation, $\mathrm{p}$ is proportion of willingness to donate and $\mathrm{d}$ is $5 \%$ absolute error. Ensuring that the resulting sample should represent both Qatari and nonQatari households, 1044 households surveyed between October-November 2016 were included in the study.

\section{Statistical Methods}

Frequency with percentages for categorical characteristics of demographic and general inquiry was calculated. Mean \pm standard deviations for each domain index such as 
knowledge, attitude, behavioral belief, normative belief, control belief, and intention were calculated after coding their items " 1 " and " 0 " for yes and no or correct and wrong response to the dichotomous questions and items having categories yes, no/don't know, maybe in the questionnaire as 2, 0, 1 as well as five levels Likert scale "Strongly disagree", "Disagree", "Neither agree nor disagree", "Agree" and "Strongly agree" as "-2", “-1", “0”, “+1" and “+2", respectively. $^{12}$ The formula $\sum$ (items response) $/ \sum$ (highest values in the items) is used to calculate an individual index for each domain. The coded items were used to make qualitative data at par with quantitative so that further parametric statistical tools could be used. Domain indices being continuous and normal distributed were compared using Student's $t$-tests (unpaired) for opt-in vs opt-out groups whereas; chisquare tests were applied to see an association between the two for categorical variables gender, nationality, heard of organ donation, et cetera. Multivariate logistic regression was applied to important and significant variables at univariate level $(\mathrm{p} \leq 0.10)$ for opt-out consent in comparison to opt-in consent. Adjusted ORs and 95\% C.I. were presented in the table. C-statistics in the form of the area under the curve (AUC) and 95\% C.I. were calculated to see how well the regression model was able to discriminate for opt-out consent. Bootstrapping (re-sampling) method, introduced by Efron (1979), was used for calculating bias-corrected percentile intervals (BCa) using 200 re-samples to make a traditional multivariate regression model to realistic model for the population. Attitude level (prevalence (s)) was used for calculating pre-odds whereas; post odds had been performed using formula (pre-odds $\mathrm{x}$ Likelihood ratio for opt-out consent $(\mathrm{LR}+$ ) from the regression model) for calculating various future/posterior probabilities at different attitude levels for opt-out consent. P-value $\leq 0.05$ (two-tailed) was considered for a statistically significant level. SPSS 22.0 statistical package was used for the analysis. ${ }^{15}$

\section{Results}

Out of 1044 survey participants, 724 (69.34\%) participants aged $37.7 \pm 10.4$ agreed to have an opt-out consent system of which 231 (29.4\%) were Qatari citizens and 511 $(70.6 \%)$ were non-Qatari residents. Among the participants in the opt-out category, there were $353(48.8 \%)$ males and $371(51.2 \%)$ females. Most of them, 221 $(30.5 \%)$ were employed in government sectors and 340 (47\%) were having a household income below 10,000 QAR/month. A majority of them 587 (81.1\%) practiced Islam religion, $93(12.8 \%)$ were Christians and only 44
(6.1\%) followed other religions such as Hinduism, Jainism, etc. About 580 (80.1\%) participants were married and 275 (38\%) had dependent $\geq 6$ children. A majority, 376 $(51.9 \%)$ were having Diploma \& Graduation degree. About $86.7 \%$ heard of organ donation but very few $(3.2 \%)$ had attended an organ donation campaign. Only a few had registered for organ donation within (5.5\%) and outside Qatar (3.5\%); however, a higher number of participants $(28.9 \%)$ had donated either organ/blood, or tissue during their lifetime. Around 38.3\% spent all their life in Qatar. A little above 56\% agreed to provide family consent for organ donation. The detailed demographic and socioeconomic characteristics of the participants who opted for opt-in or opt-out consent system are given in Table 1.

\section{Knowledge About Opt-Out Consent in Organ Donation}

Seven hundred and twenty-four participants who opted for opt-out consent, $60.2 \%$ (436/724) were aware that organ donation was a transfer of organs or tissues from a dead body or a living donor to a patient. When asked about organs that could be donated, $83.1 \%$ suggested kidneys, $49.7 \%$ heart, $47.1 \%$ liver, $23.2 \%$ lungs, $19.3 \%$ pancreas, $16.7 \%$ intestine, $65.6 \%$ blood, $40.2 \%$ cornea, $19.1 \%$ skin, $15.3 \%$ bone and $26.2 \%$ bone marrow. About $47.2 \%$ knew that there is an organ donor registry in Qatar. Seventy-four percent knew that organ donation registration could be done at 18 years and above while $10.6 \%$ opined organs could be donated at any age. When asked what death meant to the participants, $71 \%$ expressed that it meant no heartbeat and no breath; lesser number (18.1\%) understood that death meant brain death with heart beating on a ventilator; $10.5 \%$ individuals lacked clarity about death and $0.4 \%$ had differing views about death. Around $67.4 \%$ had knowledge that their religion allows organ donation. Only a few participants knew someone who is either a family member $(10.5 \%)$ or a friend $(12.6 \%)$ or a colleague $(1.4 \%)$ had donated organs or tissues while $74.5 \%$ did not know anyone donated organs or tissues during their lifetime. About $60.4 \%$ knew that part of the liver could be donated to their relatives during their lifetime and nearly $36.2 \%$ opined that this involved health risk. Eighty-seven percent knew that one of the two kidneys could be donated and $73.2 \%$ knew that it is safe. The majority of the participants were aware that Qatar's organ donation policy prohibits buying and selling of organs (63.7\%) and $61.2 \%$ were aware that it provides access to transplant facilities for all nationalities equally. 
Table I Demographic and Socioeconomic Characteristics of Survey Participants According to Opt-In and Opt-Out Consent for Organ Donation Registration

\begin{tabular}{|c|c|c|c|c|}
\hline Variable & Category & Opt-In, 320 (\%) & Opt-Out, 724 (\%) & $P$ value \\
\hline Nationality & $\begin{array}{c}\text { Qatari } \\
\text { Non-Qatari }\end{array}$ & $\begin{array}{c}73(22.8) \\
247(77.2)\end{array}$ & $\begin{array}{l}23 I(29.4) \\
5 I I(70.6)\end{array}$ & 0.03 \\
\hline Age in years & - & $38.4 \pm 11.2$ & $37.7 \pm 10.4$ & 0.37 \\
\hline Gender & $\begin{array}{l}\text { Male } \\
\text { Female }\end{array}$ & $\begin{array}{l}156(48.8) \\
164(51.2)\end{array}$ & $\begin{array}{l}353(48.8) \\
37 I(5 I .2)\end{array}$ & 0.99 \\
\hline Heard of Organ Donation & Yes & $264(82.5)$ & $628(86.7)$ & 0.07 \\
\hline Attended Organ Donation Campaign & Yes & $6(1.9)$ & $23(3.2)$ & 0.12 \\
\hline Register for Organ Donation & $\begin{array}{c}\text { Qatar } \\
\text { Outside Qatar } \\
\text { Not Registered }\end{array}$ & $\begin{array}{c}10(3.1) \\
14(4.4) \\
296(92.5)\end{array}$ & $\begin{array}{l}40(5.5) \\
25(3.5) \\
659(91)\end{array}$ & 0.20 \\
\hline Donated any organ/blood/tissue & Yes & $94(29.4)$ & $209(28.9)$ & 0.87 \\
\hline Household income & $\begin{array}{l}\text { QR } \leq 10,000 \\
\text { QR } 10,00 I-20,000 \\
\text { QR } 20,00 I-30,000 \\
\text { QR }>30,001\end{array}$ & $\begin{array}{l}69(21.6) \\
144(45) \\
51(15.9) \\
56(17.5)\end{array}$ & $\begin{array}{l}14 \mid(19.5) \\
340(47) \\
144(19.9) \\
99(13.7)\end{array}$ & 0.20 \\
\hline Occupation & $\begin{array}{c}\text { Student } \\
\text { Home maker } \\
\text { Govt. employee } \\
\text { Non-Govt. employee } \\
\text { Self-employed } \\
\text { Retired } \\
\text { Unemployed }\end{array}$ & $\begin{array}{c}10(3.1) \\
100(31.3) \\
91(28.4) \\
103(32.2) \\
2(0.6) \\
10(3.1) \\
4(1.3)\end{array}$ & $\begin{array}{c}46(6.4) \\
209(28.9) \\
221(30.5) \\
202(27.9) \\
30(4.1) \\
13(1.8) \\
3(0.4)\end{array}$ & 0.003 \\
\hline Religion & $\begin{array}{c}\text { Islam } \\
\text { Christianity } \\
\text { Others }\end{array}$ & $\begin{array}{c}25 I(78.4) \\
43(13.4) \\
26(8.1)\end{array}$ & $\begin{array}{c}587(81.1) \\
93(12.8) \\
44(6.1)\end{array}$ & 0.44 \\
\hline Marital status & $\begin{array}{c}\text { Single } \\
\text { Married } \\
\text { Divorced } \\
\text { Widowed }\end{array}$ & $\begin{array}{c}4 I(12.8) \\
260(8 I .3) \\
5(1.6) \\
14(4.4)\end{array}$ & $\begin{array}{c}120(16.6) \\
580(80.1) \\
11(1.5) \\
13(1.8)\end{array}$ & 0.05 \\
\hline Family consent for organ donation & $\begin{array}{c}\text { Yes } \\
\text { No } \\
\text { Not decided }\end{array}$ & $\begin{array}{c}124(38.8) \\
137(42.8) \\
59(18.4)\end{array}$ & $\begin{array}{l}408(56.4) \\
198(27.3) \\
118(16.3)\end{array}$ & 0.001 \\
\hline All life in Qatar & $\begin{array}{l}\text { Yes } \\
\text { No }\end{array}$ & $\begin{array}{c}86(26.9) \\
234(73.1)\end{array}$ & $\begin{array}{l}277(38.3) \\
447(61.7)\end{array}$ & 0.001 \\
\hline Education & $\begin{array}{c}\text { Up to primary } \\
\text { Secondary \& higher secondary } \\
\text { Diploma \& graduation } \\
\text { Post-graduate \& above }\end{array}$ & $\begin{array}{l}26(8.1) \\
88(28.9) \\
164(51.2) \\
42(36.5)\end{array}$ & $\begin{array}{c}58(8.0) \\
217(71.1) \\
376(51.9) \\
73(63.5)\end{array}$ & 0.53 \\
\hline Number of dependents & $\begin{array}{l}\leq 3 \text { children } \\
4-5 \text { children } \\
\geq 6 \text { children }\end{array}$ & $\begin{array}{l}86(26.9) \\
115(35.9) \\
119(37.2)\end{array}$ & $\begin{array}{l}212(29.3) \\
237(32.7) \\
275(38.0)\end{array}$ & 0.56 \\
\hline
\end{tabular}


Around $63.2 \%$ knew that donated organs from deceased donors were given to the first person on the waiting list regardless of nationality. Almost $62 \%$ were aware that the donor's family is never pressurized for donation and $48.1 \%$ were only aware of the life-time health insurance given to living organ donors. Around 53.6\% were aware that Qatar charity organization provided social support to deceased donor families if they require.

\section{Attitudes Toward Opt-Out Consent in Organ Donation}

Among the 724 participants who opted for opt-out consent, 377 (52.1\%) agreed that organ donation is a good thing to promote. Also, 57.5\% agreed that registering as an organ donor could save somebody's life. About 52.6\% agreed to register as an organ donor if their family would not have any objection to allowing the donation of their organs at the time of their death. Similarly, a majority agreed to register as organ donors if they knew more about organ transplantation procedures $(57 \%)$, the viewpoint of their religion about organ donation (59\%), and information regarding where they could register $(55 \%)$. The remaining people had no opinion or disagreement with these attitudes.

\section{Behavioral, Normative and Control Beliefs Toward Opt-Out Consent in Organ Donation}

Among the participants who opted for opt-out consent, $53.3 \%(386 / 724)$ believed that organ donation whether living or after death is going to have an impact on life after death in a good way and $55.2 \%$ believed that organ donation will be rewarded by God. Also, $57.6 \%$ believed that organ donation will increase if social support is provided to the family of the deceased regardless of whether they donate or not. Very few participants of those who opted for opt-out (5.2\%) had the strong belief that doctors will not provide enough care if the patient is a registered organ donor and
$3.3 \%$ strongly believed that the organ retrieval process after death may cause body disfigurement. About 33.6\% believed that they could not find many opportunities to register as an organ donor in Qatar while 43.4\% believed otherwise. Majority of them believed that they were healthy to donate $(52.6 \%)$, and their age is fit for donation (61.6\%). Only very few $(2.9 \%)$ worried that organ donation might leave them weak or disabled. They (44.3\%) also believed that all their questions may get answers while registering for organ donation and operation procedures for obtaining organs are not discouraging (43\%). The majority of them (57.7\%) trusted the health care system in Qatar and did not have the opinion of going abroad for organ donation and transplantation. Of the few participants who had registered as organ donors in Qatar, 0.4\% believed that the process of registering as an organ donor was time-consuming. Forty-six percent of them believed that the emotions of their family members will make them feel concerned while organs are being taken; however, they believed that they will take opinion to register as an organ donor from a family member (48.1\%), my community (4.7\%), religious leader (20.9\%) and friend $(5 \%)$.

\section{Intentions to Opt-Out Consent in Organ Donation}

Upon assessing willingness to register as an organ or tissue donor among the participants who opted for optout consent, 35.4\% (256/724) participants showed interest in registering as an organ donor whereas $36.3 \%$ were not interested and $22.8 \%$ were in dilemma. The participants were willing to donate organs like kidneys (37.6\%), blood (47.5\%), heart $(21.2 \%)$, eyes $(21.3 \%)$, liver $(18.9 \%)$, skin (15.1\%), lungs (15.9\%) and bone marrow (16.1\%). Many participants $(40.1 \%)$ have a trusted religious leader and would consider organ donation after discussing with them (36.1\%) and if they are approached by an organization which they could trust $(48.2 \%)$.

Table 2 Indices Comparison According to Opt-In and Opt-Out Consent for Organ Donation Registration

\begin{tabular}{|l|c|c|c|}
\hline Variable & Opt-In Mean ISD & Opt-Out Mean \pm SD & P value \\
\hline Knowledge & $0.45 \pm 0.17$ & $0.47 \pm 0.15$ & 0.06 \\
Attitude & $0.20 \pm 0.56$ & $0.93 \pm 0.58$ & 0.001 \\
Behavioral belief & $0.34 \pm 0.49$ & $0.46 \pm 0.46$ & 0.001 \\
Normative belief & $0.27 \pm 0.22$ & $0.30 \pm 0.21$ & 0.08 \\
Control belief & $-0.24 \pm 0.52$ & $-0.28 \pm 0.58$ & 0.28 \\
Intention & $0.20 \pm 0.30$ & $0.33 \pm 0.31$ & 0.001 \\
\hline
\end{tabular}




\section{Comparison of Six Domain Indices}

Between Participants Who Opted for Opt-Out and Opt-In Consents of Organ

\section{Donation}

The indices knowledge, attitude, behavioral beliefs, normative beliefs, control beliefs, and intentions were compared between the participants who proposed for opt-out and optin consents (Table 2). Significant increase in attitudes $(0.93$ $\pm 0.58 \mathrm{Vs} 0.20 \pm 0.56)$, behavioral beliefs $(0.46 \pm 0.46 \mathrm{Vs}$ $0.34 \pm 0.49)$ and intentions $(0.33 \pm 0.31$ Vs $0.20 \pm 0.30)$ were found in the participants who opted for opt-out in comparison to opt-in consents ( $\mathrm{p} \leq 0.001$ for all).

After adjusting statistical significant variables at univariate analysis, multivariate analysis showed that attitude index was associated with opt-out system (Adjusted OR: 16.7, 95\% C. I.:10.6-26.3, $\mathrm{p}=0.001$ ) whereas; knowledge index (Adjusted OR: 0.25 , 95\% C.I.: $0.07-0.83, \mathrm{p}=0.03$ ), behavioral beliefs (Adjusted OR: 0.35, 95\% C.I.: 0.35-0.86, $\mathrm{p}=0.009$ ) and intention indices (Adjusted OR: 0.42, 95\% C.I.: 0.20-0.87, $\mathrm{p}=0.02$ ) were associated with opt-in system for organ donation in Qatar (Table 3). Figure 1 shows that the regression model has $84 \%$ discriminate accuracy for opt-out consent in the study.

\section{Bootstrap Multivariate Logistic Regression}

Table 4 demonstrates the bootstrap estimated values for the population regarding the analysis of the study. The lower and upper posterior probabilities suggested that the actual effect size of attitude in the population was not so large but consistent and significant from 2.37 to 3.35 , after adjusting other

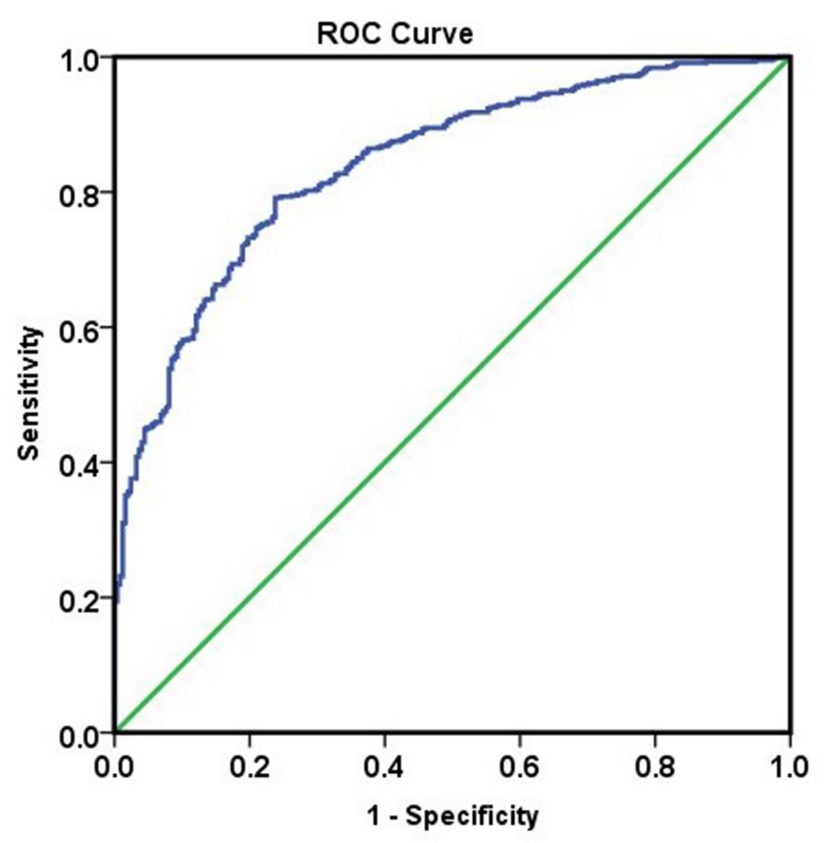

Diagonal segments are produced by ties.

Figure I ROC curve showing discriminate accuracy for opt-out consent in the model.

important variables in the model advocating that the positive attitude towards organ donation is an important factor to improve the organ donation registration in the country.

\section{Posterior Probability of an Individual According to Attitude Level}

Table 5 shows the posterior probability of an individual according to attitude level in the study. If attitude level is

Table 3 Multivariate Logistic Regression for Opt-Out Consent in Organ Donation Registration

\begin{tabular}{|c|c|c|c|c|}
\hline Variable & Category & Adjusted OR & 95\% C.I. & $P$ value \\
\hline Nationality & Qatari & 1.70 & $0.85-3.41$ & 0.14 \\
\hline All life in Qatar & Yes & 1.30 & $0.68-2.46$ & 0.44 \\
\hline \multirow[t]{3}{*}{ Family Consent for organ donation } & No & I & - & - \\
\hline & Yes & 0.75 & $0.47-1.19$ & 0.22 \\
\hline & Not decided & 0.64 & $0.37-1.11$ & 0.11 \\
\hline Knowledge index & - & 0.25 & $0.07-0.83$ & 0.03 \\
\hline Attitude index & - & 16.7 & $10.6-26.3$ & 0.001 \\
\hline Behavioral belief index & - & 0.55 & $0.35-0.86$ & 0.009 \\
\hline Normative belief index & - & 1.35 & $0.57-3.20$ & 0.50 \\
\hline Intention index & - & 0.42 & $0.20-0.87$ & 0.02 \\
\hline
\end{tabular}


Table 4 Bootstrap (200 Re-Sampling) Multivariate Logistic Regression

\begin{tabular}{|c|c|c|c|c|c|}
\hline Variable & Beta Coefficients & Bias & SE & P value & BCa 95\% C.I. \\
\hline Nationality (Qatari) & -0.51 & -0.04 & 0.355 & 0.14 & -1.21 to 0.13 \\
\hline All life in Qatar (Yes) & 0.25 & -0.005 & 0.317 & 0.42 & -0.32 to 0.85 \\
\hline Family Consent for organ donation (Yes) & -0.29 & -0.004 & 0.260 & 0.21 & -0.72 to 0.17 \\
\hline Family Consent for organ donation (Not decided) & -0.45 & 0.003 & 0.282 & 0.11 & -0.96 to 0.10 \\
\hline Knowledge index & -1.40 & -0.014 & 0.635 & 0.03 & -2.55 to 0.20 \\
\hline Attitude index & 2.81 & 0.033 & 0.243 & 0.01 & 2.37 to 3.35 \\
\hline Behavioral belief index & -0.60 & -0.039 & 0.237 & 0.02 & -1.07 to -0.26 \\
\hline Normative belief index & 0.30 & -0.003 & 0.493 & 0.55 & -0.69 to 1.34 \\
\hline Intention index & -0.87 & 0.036 & 0.367 & 0.01 & -1.60 to -0.3 \\
\hline Constant & 0.78 & 0.039 & 0.431 & 0.08 & -0.29 to 1.86 \\
\hline
\end{tabular}

0.70 of an individual or $70 \%$ is in favor of a positive attitude towards organ donation, the chances of the individual opting for opt-out consent become 0.97 , stating that there is a $97 \%$ chance that the individual will consider optout consent. It also depicted that as an attitude level increased the lower and upper posterior probabilities in the population ie 0.85 to 0.89 .

\section{Discussion}

From this survey, it was found that Qatar's household population expressed opt-out consent as a "good way" to register people for organs donation. Most participants opted for an opt-out consent system than the opt-in consent for organ donation. Previous studies have shown that opt-out consent policies are associated with higher organ donation rates. ${ }^{16,17}$ Mossialos et al indicated that countries with a presumed consent rule had respondents with a greater ability to donate both their organs and those of a relative. ${ }^{18}$ This is supported by another report which analyzed data from 24 countries and found that in areas with presumed consent laws, there was an $18 \%$ increase in organ donation rates. ${ }^{19,20}$
After the implementation of presumed consent, most European countries showed an increase in organ donation rates. ${ }^{17}$ The rate of organ donation in Austria multiplied fourfold since the presumed consent was made legal in 1982. ${ }^{21}$ Likewise, in Spain, there was a massive increase in organ donation after the introduction of the Spanish Model. Organ donation rate has increased from 14.3 per million population (pmp) in 1989 to $33.6 \mathrm{pmp}$ in 1999, reflecting a $142 \%$ increase. $^{22}$ Opt-out programs boost not only the long-term organ donation rate but also bring about immediate beneficial effects in some countries. The kidney transplant rate in Belgium increased by $86 \%$ after two years of implementation of presumed consent. ${ }^{7}$ A similar increase in organ donation will benefit transplant patients globally, as 5000 people were waiting in the UK for kidney transplants in 2019. ${ }^{23}$ Following the introduction of the opt-out program in 2015, there was a rise in organ donors in Wales. Over the first six months following the introduction of the opt-out program, more than half of the transplanted organs (32 of 60) were donated from patients whose consent was presumed and could not have been obtained otherwise. ${ }^{24}$ On the other hand, Brazil has reported a decrease in organ donation rate after the

Table 5 Individual Attitude Level and Posterior Probabilities for Opt-Out Consent

\begin{tabular}{|l|l|l|l|l|l|l|l|c|c|}
\hline \multicolumn{8}{|c|}{ Before Bootstrap Posterior Probabilities of Opt-Out Consent in the Study } \\
\hline Attitude level & 0.20 & 0.30 & 0.40 & 0.50 & 0.60 & 0.70 & 0.80 & 0.90 \\
\hline Pre-Odds & 0.25 & 0.42 & 0.67 & 1.0 & 1.5 & 2.3 & 4.0 & 9.0 \\
Post-Odds & 4.18 & 7.0 & 11.2 & 16.7 & 25.0 & 38.4 & 66.8 & 150.3 \\
Posterior Probability & 0.80 & 0.88 & 0.92 & 0.95 & 0.96 & 0.97 & 0.99 & 0.993 \\
\hline \multicolumn{7}{|c|}{ After Bootstrap Lower and Upper Posterior Probabilities of Opt-Out Consent in the Population } \\
\hline Lower & 0.37 & 0.50 & 0.62 & 0.70 & 0.78 & 0.85 & 0.90 & 0.96 \\
Upper & 0.45 & 0.58 & 0.69 & 0.77 & 0.84 & 0.89 & 0.93 & 0.97 \\
\hline
\end{tabular}


implementation of the presumed consent in 1998 where there were other factors such as lack of transplant coordination infrastructure, including a national waiting list and a cohesive mechanism for individuals to refuse to be donors impacted more to it. However, the adoption of the presumed consent program created a public panic in Brazil that ultimately repealed the presumed consent law within a year and reverted to an opt-in registration scheme for organ donation. $^{25}$

More than half of the survey participants (52.1\%) were of the view that it is good to promote organ donation. Also, 52.6\% had the opinion that they would be able to register as an organ donor, if their parents did not have any objection at the time of their death to give consent to the procedure. Currently, family members' refusal to donate a relative's organs is a barrier to increasing the number of donors of organs worldwide. ${ }^{26}$ Previous studies suggest that people were far more willing to donate their organs than to give consent to the family. ${ }^{14}$ On the other hand, after the implementation of presumed consent in Wales, an increase in family consent from $44.4 \%$ in 2014 to $64.5 \%$ in 2017 was observed. ${ }^{27}$ Often, the poor consenting of the family may be due to the family's misunderstanding of their relative's intention to donate their organs. It is therefore of utmost importance to address one's intention to donate organs with their family and receive their approval, as becoming an organ donor is often determined by one's relatives. ${ }^{28}$ A European survey identified the positive correlation between discussions on organ donation with family and willingness to donate organs. ${ }^{18}$ Morgan et al stated that knowledge, attitude, and altruism are significantly related to family discussions and therefore a donor card is signed. $^{29}$ The quality of discussions between the potential donors and their families depends on how well the donors can address vital issues raised by family members regarding organ donation. ${ }^{29}$ Therefore, the decision to communicate with family members depends on the level of knowledge and attitudes of potential donors as they require to clarify all the doubts of the family members regarding organ donation. In our study, nearly half of the participants $(48 \%)$ were ready to take the opinion of the family members before registering as an organ donor that will probably have a positive impact on organ donation.

Our results showed a high attitude index for opt-out consent among participants and the results were consistent with the Theory of Planned Behavior where the attitudes of an individual towards a behavior influence the intention of a person to perform that behavior. The previous study demonstrated a positive attitude to one's ability to donate organs $^{30}$ while few studies showed the public's adverse approach to organ donation. ${ }^{31}$

Also, for the first time in the world, we examined the framework for estimating the potential probability of optout consent on behalf of the population's prevalent attitude. We had already found an overall index of attitude amongst Qatar's household population $0.70 \pm 0.66$ (70\%). In the current study, we found that if an individual's attitude rate is $0.70 \%$ or $70 \%$, the individual's chances of opting-out consent will be 0.97 , meaning that there is a $97 \%$ chance that the individual would opt for an optingout consent system. It also showed that the lower and upper posterior probabilities increased in population ie ( 0.85 to 0.89$)$ as the rate of attitude increased. It is, therefore, necessary to maintain a high attitude towards organ donation among people, so that people can support a change from opt-in to an opt-out system in the current consent process that can optimize and promote organ donation and transplantation in the country.

However, few studies reported that the transition to an "opt-out" organ procurement scheme is not enough to resolve the crucial gap between demand for organs and supply. ${ }^{32-34}$ The effectiveness of the consent system for organ donation involves systematic and ongoing efforts to increase public awareness and to correct misconceptions. ${ }^{34}$ Adequate knowledge and a positive attitude could play a key role in shaping the public opinion on consent process and thereby to become an organ donor. Hence, with the above-described model, the probabilities of willingness to register as an organ donor could be established by estimating people's attitude.

\section{Conclusion}

The current survey findings suggest that a switch from an opt-in to an opt-out consent system may have the potential to increase organ donor registration, thereby increase in transplantation among patients saving human lives which could easily be achieved by increasing the attitude towards organ donation registration among people. The potential probability of an opt-out consent system among any population could be estimated on behalf of that population's prevalent attitude as indicated by Bootstrap posterior probability (s) in this study.

\section{Limitations}

The regression procedure for categorical dependent variable do not have collinearity diagnostics. Hence, a linear 
regression procedure for continuous dependent variable was used to diagnose collinearity between predictor variables of the model. Collinearity statistics in the form of variance inflation factor (VIF) were calculated. The VIFs were between 1.05 to 2.42 , less than 5 for each independent variable, and thus reducing the chance of collinearity in the model. Qatar population being unique in the world, the results of the study may not be appropriate to generalize for other populations.

\section{Strength of the Study}

The bootstrapping method was used to make a traditional multivariate regression model to realistic model for the population to predict posterior probabilities at different attitude levels (prevalence (s)) using pre-odds and postodds. This method can be used for calculating posterior probabilities in similar epidemiological studies.

\section{Data Sharing Statement}

The study data are available at Cardiology Research Center, Medical Research Center, HMC.

\section{Acknowledgment}

We appreciate Mr. Nasser Saleh AL Mahdi (Director, Censuses, Surveys \& Statistical Methods Department, Qatar), Dr. Noora Jamaan Al Abdullah (Head section of statistical methods \& sampling, Censuses, Surveys \& Statistical Methods Department, Qatar), and the MDPS staff for their timely support in conducting the household survey. We also thank survey participants for their valuable contribution which made the survey possible.

\section{Funding}

The study is Qatar National Research Fund (QNRF), Qatar sponsored under national Priority Research Proposal (NPRP-7-965-3-247). QNRF had no role in the study design, data collection, data analysis, and decision to publish. Open Access funding for the manuscript provided by Qatar Nation Library (QNL), Doha, Qatar.

\section{Disclosure}

The authors declare no conflicts of interest in this work.

\section{References}

1. Nathan HM, Conrad SL, Held PJ, et al. Organ donation in the United States. Am J Transplant. 2003;3(4):29-40. doi:10.1034/j.1600-6143.3. s4.4.x
2. United network for organ sharing. National data. Available from: www.unos.org/data. Accessed September 6, 2020.

3. Chapman J, Bock A, Dussol B, et al. Follow-up after renal transplantation with organs from donors after cardiac death. Transpl Int. 2006;19(9):715-719. doi:10.1111/j.1432-2277.2006.00337.x

4. Vincent A, Logan L. Consent for organ donation. $\mathrm{Br} J$ Anaesth. 2012;108(1):i80-i87. doi:10.1093/bja/aer353

5. Koffman G, Singh I. Presumed consent: the way forward for organ donation in the UK. Ann R Coll Surg Engl. 2011;93(4):268-270.

6. Wilkinson TM. Individual and family decisions about organ donation. J Appl Philos. 2007;24(1):26-40. doi:10.1111/j.14685930.2007.00339.x

7. Michielsen P. Presumed consent to organ donation: 10 years' experience in Belgium. $J$ R Soc Med. 1996;89(12):663-666. doi:10.1177/ 014107689608901203

8. Li D, Hawley Z, Schnier K. Increasing organ donation via changes in the default choice or allocation rule. J Health Econ. 2013;32 (6):1117-1129. doi:10.1016/j.jhealeco.2013.09.007

9. Arshad A, Anderson B, Sharif A. Comparison of organ donation and transplantation rates between opt-out and opt-in systems. Kidney Int. 2019;95(6):1453-1460. doi:10.1016/j.kint.2019.01.036

10. Thaler RH. Opting in vs. opting out. The New York Times. Archived from the original on March 8, 2014. 2009 September 26. Accessed September 6, 2020.

11. Singh R, Varughese B, El-Menyar A, et al. Prevalence of socio-demographic and behavioral factors about organ donation in Qatar: a household survey. Qatar Med J. 2020;5.

12. Singh R, Agarwal TM, Al Thani H, et al. Validation of a survey questionnaire on organ donation: an Arabic world scenario. J Transplant. 2018;1-10.

13. Ajzen I. The theory of planned behavior. Organ Behav Hum Decis Process. 1991;50(2):179-211. doi:10.1016/0749-5978(91)90020-T

14. Zaidan M, Singh R, Wazaify M. Physicians' perceptions, expectations, and experience with pharmacists at hamad medical corporation in Qatar. J Multidiscip Healthc. 2011;4:85-90. doi:10.2147/JMDH. S14326

15. Field A. Discovering Statistics Using SPSS. London: SAGE Publication; 2005.

16. Rithalia A, Mcdaid C, Suekarran S, et al. Impact of presumed consent for organ donation on donation rates: a systematic review. $B M J$. 2009;338(jan14 2):a3162-a3162. doi:10.1136/bmj.a3162

17. Abadie A, Gay S. The impact of presumed consent legislation on cadaveric organ donation: a cross-country study. J Health Econ. 2006;25(4):599-620. doi:10.1016/j.jhealeco.2006.01.003

18. Mossialos E, Costa-Font J, Rudisill C. Does organ donation legislation affect individuals' willingness to donate their own or their relative's organs? Evidence from European Union survey data. BMC Health Serv Res. 2008;8(1):48. doi:10.1186/14726963-8-48

19. Bilgel F. The impact of presumed consent laws and institutions on deceased organ donation. Eur J Health Econ. 2012;13(1):29-38. doi:10.1007/s10198-010-0277-8

20. Willis BH, Quigley M. Opt-out organ donation: on evidence and public policy. J R Soc Med. 2014;107(2):56-60. doi:10.1177/ 0141076813507707

21. Gnant MFX, Wamswer P, Geotzinger P, et al. The impact of the presumed consent law and a decentralized organ procurement system on organ donation: quadruplication in the number of organ donors. Transplant Proc. 1991;23(5):2685-2686.

22. Matesanz R, Dominguez-Gil B, Coll E, et al. Spanish experience as a leading country: what kind of measures were taken? Transpl Int. 2011;24(4):333-343. doi:10.1111/j.1432-2277.2010.01204.x

23. NHS Blood and Transplant. (2018) Annual Report on Kidney Transplantation: Report for 2017/18 (NHS Blood and Transplant/ NHS England). Available from: https://www.organdonation.nhs.uk/ become-a-living-donor/. Accessed September 6, 2020. 
24. Llywodraeth Cymru- Welsh Government. Lives saved in first six months of new organ donation system. [Press release]; June 14, 2016. Available from: https://gov.wales/lives-saved-first-six-monthsnew-organ-donation-system-0. Accessed September 6, 2020.

25. Ezaz G, Lai M. How the "opt-in" option optimizes organ donation rates. Dig Dis Sci. 2019;64(5):1067-1069. doi:10.1007/s10620-01905483-z

26. Ghorbani F, Khoddami-Vishteh HR, Ghobadi O, et al. Causes of family refusal for organ donation. Transplant Proc. 2011;43 (2):405-406. doi:10.1016/j.transproceed.2011.01.031

27. Young V, McHugh S, Glendinning R, et al. Evaluation of the human transplantation (Wales) act: impact evaluation report; 2017. Available from: https:/gov.wales/sites/default/files/statistics-and-research /2019-05/evaluation-human-transplantation-wales-act-impact.pdf. Accessed September 6, 2020.

28. Fernandes ME, Bittencourt ZZ, Boin Ide F. Experiencing organ donation: feelings of relatives after consent. Rev Lat Am Enfermagem. 2015;23(5):895-901. doi:10.1590/0104-1169.048 6.2629

29. Morgan SE, Miller JK. Beyond the organ donor card: the effect of knowledge, attitudes, and values on willingness to communicate about organ donation to family members. Health Commun. 2002;14 (1):121-134. doi:10.1207/S15327027HC1401_6
30. Brkljacic T. Tissue and organ donation: the relationship between attitude structure and intention to donate. Drustvena Istraz. 2002;11 (4-5):725-749.

31. Morgan M, Kenten C, Deedat S, et al. Attitudes to deceased organ donation and registration as a donor among minority ethnic groups in North America and the UK: a synthesis of quantitative and qualitative research. Ethn Health. 2013;18(4):367-390. doi:10.1080/ 13557858.2012.752073

32. Symvoulakis E, Markaki A, Rachiotis G, et al. Organ donation attitudes and general self-efficacy: exploratory views from a rural primary care setting. Rural Remote Health. 2019;19(4):5241. doi:10.22605/RRH5241

33. Symvoulakis EK, Anyfantakis D, Morgan M. Organ donation and new policies: do we need to act less generally and more locally? JAMA Intern Med. 2015;175(12):1999. doi:10.1001/jamainternm ed. 2015.6520

34. Symvoulakis EK, Rachiotis G, Papagiannis D, et al. Organ donation knowledge and attitudes among health science students in Greece: emerging interprofessional needs. Int J Med Sci. 2014;11(6):634-640. doi:10.7150/ijms.8686
Journal of Multidisciplinary Healthcare

\section{Publish your work in this journal}

The Journal of Multidisciplinary Healthcare is an international, peerreviewed open-access journal that aims to represent and publish research in healthcare areas delivered by practitioners of different disciplines. This includes studies and reviews conducted by multidisciplinary teams as well as research which evaluates the results or conduct of such teams or healthcare processes in general. The journal

\section{Dovepress}

covers a very wide range of areas and welcomes submissions from practitioners at all levels, from all over the world. The manuscript management system is completely online and includes a very quick and fair peer-review system. Visit http://www.dovepress.com/testimonials. php to read real quotes from published authors. 